\title{
Differential Effects of Midazolam and Zolpidem on Sleep-Wake States and Epileptic Activity in WAG/Rij Rats
}

\author{
H. DEPOORTERE, ${ }^{* 1}$ D. FRANCCON,* E. L. J. M. VAN LUIJTELAAR, $\dagger$ \\ W. H. I. M. DRINKENBURG $\dagger$ AND A. M. L. COENEN $\dagger$ \\ *Synthélabo Recherche (L.E.R.S.), 31, avenue Paul Vaillant Couturier, F-92220 Bagneux, France \\ $\uparrow N I C I$, Department of Psychology, University of Nijmegen, Nijmegen, The Netherlands
}

Received 1 September 1994; Revised 14 January 1995; Accepted 17 January 1995

\begin{abstract}
DEPOORTERE, H., D. FRANCON, E. L. J. M. VAN LUIJTELAAR, W. H. I. M. DRINKENBURG AND A. M. L. COENEN. Differential effects of midazolam and zolpidem on sleep-wake states and epileptic activity in WAG/ Rij rats. PHARMACOL BIOCHEM BEHAV 51(4) 571-576, 1995.-Hypnotic drugs are known to possess antiepileptic activity. Therefore, the effects of the benzodiazepine hypnotic midazolam $(10 \mathrm{mg} / \mathrm{kg})$ and the novel imidazopyridine hypnotic zolpidem $(10 \mathrm{mg} / \mathrm{kg})$ on sleep-wake states and on the number of spike-wave discharges were evaluated in WAG/Rij rats. Rats of this strain are considered to bc a model for generalized absence epilepsy. Animals were implanted with chronic monopolar EEG electrodes and, after recovery from surgery, the EEG was recorded for $6 \mathrm{~h}$ during the dark period on 3 consecutive days. Sleep recordings were analyzed using Hjorth's parameters and number and duration of spike-wave discharges were visually determined. It was found that both drugs facilitated nonREM sleep at the cost of wakefulness. Both hypnotics also reduced the number and duration of spike-wave discharges. The initial decrease after midazolam, however, was followed by a rebound reflecting a poorer quality of vigilance expressed as an increase in spike-wave discharges. The strong antiabsence activity of zolpidem mimics that of midazolam and is well correlated with their equipotent hypnotic action and anticonvulsant effect in the isoniazid test.
\end{abstract}

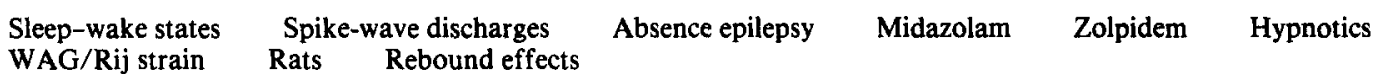

FOR THE last 2 decades benzodiazepines have been the anxiolytics and hypnotics of first choice due to their efficacy, their relatively mild side effects, and their safety. A standing problem is that they also induce daytime drowsiness, which is often accompanied by muscular relaxation (6). Moreover, it has become increasingly clear that benzodiazepines affect cognitive functioning and psychomotor performance $(16,20,25)$. Next to all these actions, benzodiazepines show broad spectrum antiepileptic properties: they reliably reduce various types of convulsions and counteract spike-wave discharges.

Until recently, it was generally assumed that these different effects of benzodiazepines are indissolubly linked. Nowadays, research efforts are aimed at separating the different actions of the benzodiazepines, and new drugs are currently being developed that do not possess all the effects of the benzodiazepines. Investigations of partial agonists at the benzodiazepine
( $\omega)$ receptors suggest that it is, indeed, possible to separate these effects. Concrete examples were presented by Coenen and van Luijtelaar (3), who demonstrated that the hypnotic and antiepileptic action of ZK 91296 were discriminable. Stephens et al. (24) and Coenen et al. (5) also showed that the anxiolytic and hypnotic actions of abecarnil were distinguishable.

The novel hypnotic, zolpidem, an imidazopyridine derivative, shares many of the pharmacological actions characteristic of benzodiazepines. There are, however, differences such as the weaker myorelaxant effects of zolpidem $(1,10)$. Depoortere et al. (10) investigated the anticonvulsant profile of zolpidem in pentylenetetrazol-induced convulsions and in the electroshock model. They demonstrated a considerable weaker anticonvulsant activity for zolpidem than for the benzodiazepines midazolam, triazolam, and flunitrazepam in

\footnotetext{
'To whom requests for reprints should be addressed.
} 
these models. However both categories of drugs, ligands of the GABA-benzodiazepine receptor complex, have equipotent hypnotic activity (11), as well as anticonvulsant effects in the isoniazid convulsant model (30). Based on the latter findings, it is likely that zolpidem, like the benzodiazepines, inhibits spike-wave discharges.

The purpose of the present study was to evaluate the effects on sleep-wake states and on the amount of epileptic activity of the classical benzodiazepine hypnotic midazolam and the nonbenzodiazepine hypnotic zolpidem. This was done in WAG/Rij rats, which show spontaneously occurring spikewave discharges in the EEG and are considered as an adequate model for human absence epilepsy $(4,27)$.

\section{METHOD}

Experiments were performed on 10 male WAG/Rij rats, weighing between 320 and $400 \mathrm{~g}$. They were maintained under identical environmental conditions, under a $12 \mathrm{~L}: 12 \mathrm{D}$ cycle and a constant temperature of $21^{\circ} \mathrm{C}$. Rats were anesthetized with an intraperitoneal injection of $50 \mathrm{mg} / \mathrm{kg}$ sodium pentobarbital and implanted with three small electrode screws on each hemisphere. The first electrode was screwed into the skull above the sensorimotor cortex $(1.5 \mathrm{~mm}$ lateral to the median suture and $1.5 \mathrm{~mm}$ behind the fronto-parietal suture), the second one into the skull above the visual cortex $(1.5 \mathrm{~mm}$ lateral to the median suture and $1.5 \mathrm{~mm}$ in front of the parietooccipital suture), and the third one above the cerebellum. The latter served as a reference electrode. All electrodes were attached to a seven-lead Winchester connector fixed with dental cement to the cranium. Three weeks of postoperative recovery were allowed. During this period, half of the rats were habituated to a reversed light : dark cycle, whereas the other half kept the regular cycle with lights on between 0700 and $1900 \mathrm{~h}$. There was no difference between the two groups of five rats: they had the same ages and weights $(360 \pm 20 \mathrm{~g})$. Four days before the experiment, the animals were placed in Plexiglas cylinders with free access to food and water (habituation period to experimental conditions). Each rat was injected twice at intervals of at least 3 weeks and recorded from $1100-1700 \mathrm{~h}$. Experiments with $10 \mathrm{mg} / \mathrm{kg}$ PO of zolpidem or midazolam were conducted during 3 consecutive days in five rats habituated to a reversed light : dark cycle, as this is the condition required to observe a hypnotic cffect of midazolam (9). The first day being a first control day (vehicle, distilled water), followed by a drug day (either zolpidem or midazolam), and again followed by a second control day (vehicle). The dose of $10 \mathrm{mg} / \mathrm{kg}$ PO was chosen for both zolpidem and midazolam because of their equal potencies on sleep-wake states in normal rats (9-11). The other five rats were recorded during the light period after treatment with vehicle (control day) on two occasions at interval of 3 weeks.
Three sleep-wake states were differentiated, as follows $(7,9)$ : wakefulness (W; characterized by low voltage fast EEG activity), non-REM sleep (drowsiness and slow-wave sleep characterized by larger EEG activity and by high amplitude slow waves with bursts of sleep spindles), and paradoxical sleep or REM sleep (characterized by periods of hypersynchronous theta rhythm in the visual area and low-voltage EEG activity in the sensorimotor area).

The EEG was automatically analyzed by a computerized system that discriminates between these states. The system, which uses Hjorth's descriptors, has been described in detail, validated, and extensively used $(8,15)$. The performance of the system was regularly checked against visual scoring. Baseline parameters for the light and dark period were determined, while drug effects were only evaluated in the dark period, the most sensitive part of the light : dark cycle to evaluate hypnotic effects and antiabsence effect on spike-wave discharges $(9,28,29)$. Spike-wave discharges were counted based on criteria published elsewhere, whereby the number and total duration of the spike-wave discharges per hour were determined (27). Within-group comparisons were made with Student's $t$ test for paired observations.

\section{RESULTS}

Sleep-wakefulness characteristics for the baseline light and dark period are presented in Table 1. This table shows that the rats predominantly slept during the light period ( $74 \%$ of total time) and that the percentages of non-REM sleep and REM sleep, the number of REM periods, and the mean length of periods of REM sleep were greater in the light than in the dark period. The rats had more spike-wave discharges during the dark period (mean and standard error: $197 \pm 21$ ) than during the light period $(85 \pm 8)$.

Zolpidem reduced wakefulness and increased non-REM sleep during the first $\mathbf{2} \mathrm{h}$ following administration. No significant effects were seen on REM sleep. The data are shown in Fig. 1a. One day later, non-REM sleep was reduced and wakefulness was increased for the first hour of recording.

Zolpidem decreased the number and total duration of spike-wave discharges (Fig. 2a). These effects were present during the first $3 \mathrm{~h}$ after administration. The number and duration of the spike-wave discharges on the postdrug day did not differ from predrug values, except that the duration was still reduced during the first hour on the postdrug day.

Midazolam increased non-REM sleep and reduced wakefulness. The results are shown in Fig. 1b. Midazolam reduced the number and duration of spike-wave discharges during the first $3 \mathrm{~h}$ following drug administration (Fig. 2b). This initial decrease was followed by a significant increase in number and total duration at the fifth hour of the experimental day. The total duration of the spike-wave discharges was still enhanced

TABLE 1

SLEEP-WAKEFULNESS PARAMETERS OF WAG/Rij RATS RECORDED DURING THE LIGHT AND THE DARK PERIOD (MEAN OF TWO EXPERIMENTS ON FIVE RATS)

\begin{tabular}{lcrrrrrr}
\hline Recordings During & W\% & non-REM\% & REM\% & nREM & xREM s & nSWD & dSWD s \\
\hline Light & $24.2 \pm 1.5$ & $65.4 \pm 1.1$ & $10.4 \pm 1.3$ & $19 \pm 1$ & $116 \pm 7$ & $85 \pm 8$ & $440 \pm 82$ \\
Dark & $59.2 \pm 2.5$ & $38.6 \pm 2.5$ & $2.2 \pm 0.8$ & $7 \pm 2$ & $89 \pm 3$ & $197 \pm 21$ & $1534 \pm 159$ \\
\hline
\end{tabular}

The results ( \pm SEM) are expressed as percentages for wakefulness $(W)$, nonREM sleep, REM sleep, number of REM periods (nREM), mean duration of REM periods in s ( $\mathrm{x} R E M)$, number of spike-wave discharges (nSWD), and total duration of spike-wave discharges in seconds (dSWD) in a 6-h recording period during the first control day. 

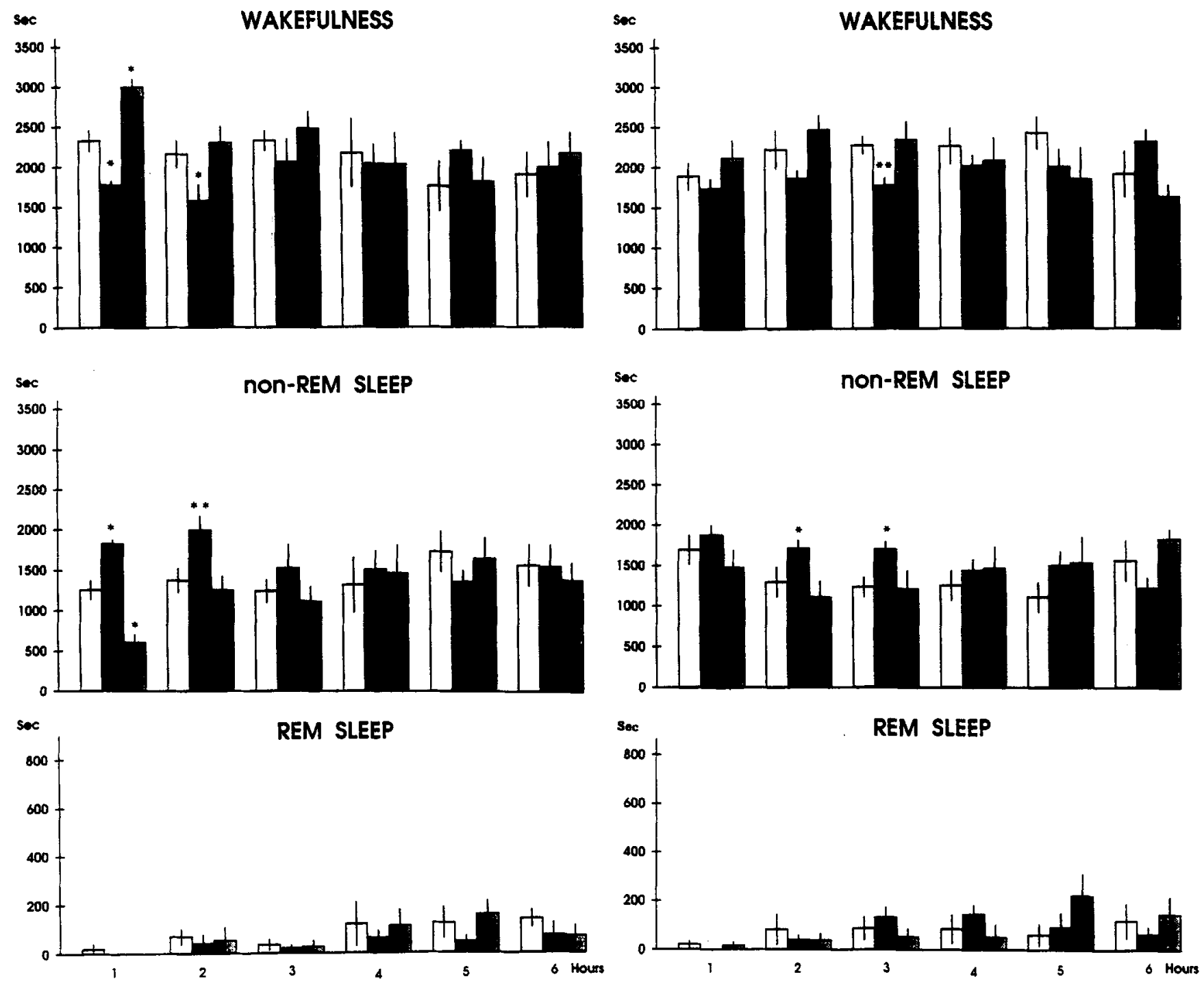

(a) $\square$ CONIROL DAY $\square$ ZOLPIDEM (10 mo/kg DO; n 5 ) SECOND CONIROL DAY

(b) $\square$ CONIROL DAY MIDAZOLAM (10 mg/kg DO; n-5) SECOND CONTROL DAY

FIG. 1. (a) Effects of zolpidem ( $10 \mathrm{mg} / \mathrm{kg} \mathrm{PO})$ on sleep-wake states in WAG/Rij rats recorded during the dark period $(n=5)$. ${ }^{*} p \leq 0.05 ;{ }^{* *} p$ $\leq 0.01$ vs. control values. (b) Effects of midazolam $(10 \mathrm{mg} / \mathrm{kg}$ PO) on sleep-wake states in WAG $/$ Rij rats recorded during the dark period $(n=$ 5 ). ${ }^{*} p \leq 0.05 ;{ }^{* *} p \leq 0.01$ vs. control values.

on the sixth hour after administration and during the first hour on the postdrug day; this was followed by a steady decline to predrug levels.

An overview of the main outcomes is presented in Table 2. Both drugs facilitated non-REM sleep at the expense of wakefulness and reduced the number and duration of spikewave discharges with a similar efficacy. On the second control day, the two drugs differed in that zolpidem decreased non-REM sleep and the number of spike-wave discharges while midazolam increased spike-wave activity.

\section{DISCUSSION}

The sleep-wakefulness profile of WAG/Rij rats differs from that commonly seen in other laboratory rats. The low percentage REM sleep for the dark period $(2 \%)$ seems to be smaller than commonly reported $(5 \%)(2,9,18,26)$. Also, the duration of the REM periods seems to be shorter than found earlier for outbreds in the same laboratory (7). Thus, it seems that WAG/Rij rats spend less time in REM sleep than other rats, and this was directly evaluated by Gandolfo et al. (13) who reported that WAG/Rij rats have less REM sleep periods per hour, with a lower percentage of REM sleep, and that these rats seemed to have difficulties entering into REM sleep.

Despite differences in genotype between outbred and WAG/Rij rats, it seems that both midazolam and zolpidem reliably induce nonREM sleep at the cost of wakefulness ( $\mathrm{Ta}$ ble 2). The hypnotic effects of zolpidem were earlier described by Depoortere et al. $(10,11)$, and the present results suggest that the hypnotic effects of both drugs are independent of the rat's genotype. However, the two drugs differ in their effects on rebound spike-wave discharges and on sleep $24 \mathrm{~h}$ following 

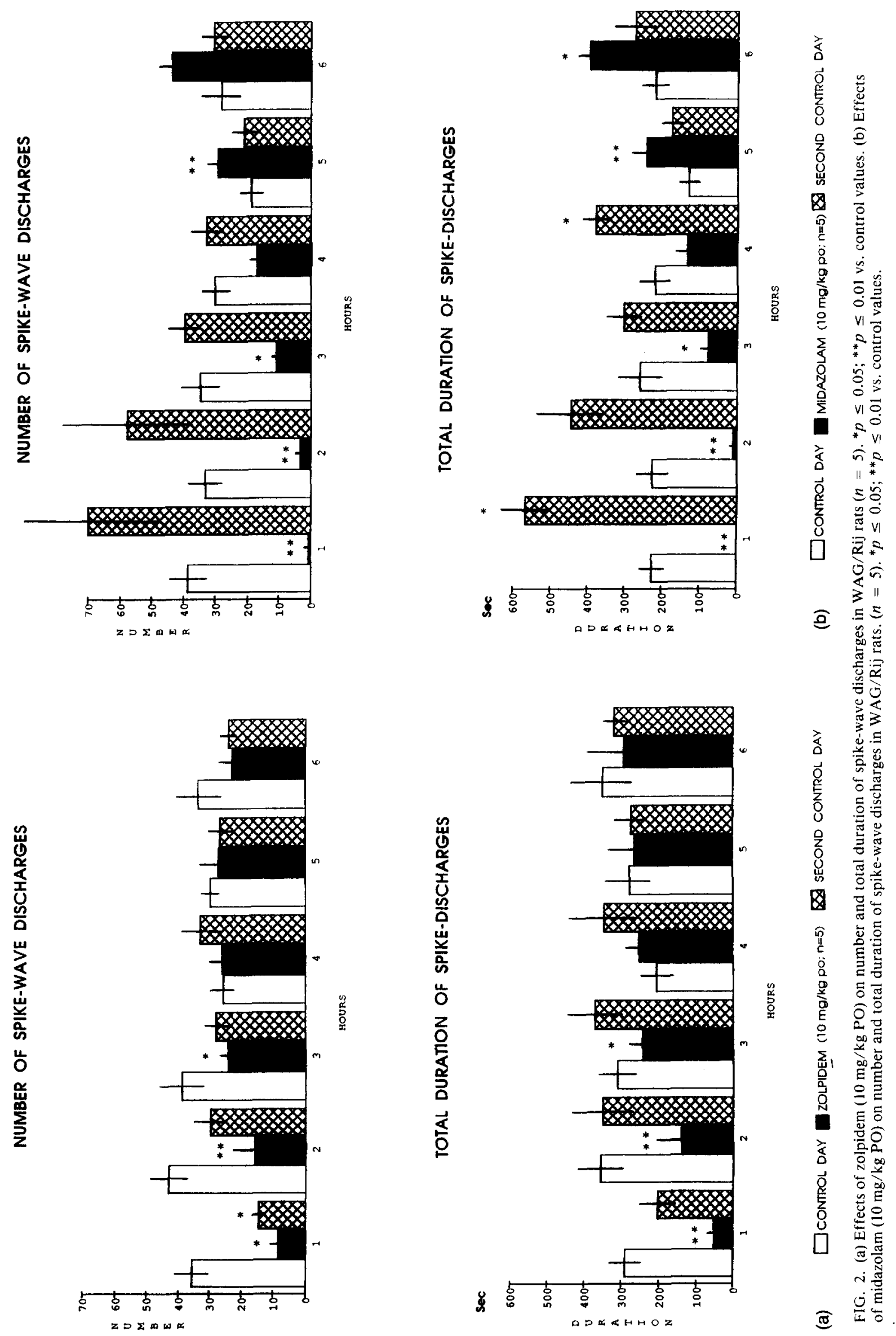
TABLE 2

EFFECTS OF ZOLPIDEM AND MIDAZOLAM ON THE SLEEP-WAKEFULNESS PARAMETERS OF WAG/Rij RATS RECORDED DURING THE DARK PERIOD ( $n=5$ PER EXPERIMENT; RECORDINGS FROM $1100-1700 \mathrm{~h}$ )

\begin{tabular}{|c|c|c|c|c|c|c|c|c|c|c|}
\hline & \multicolumn{5}{|c|}{ Zolpidenı } & \multicolumn{5}{|c|}{ Midazolan } \\
\hline & Control & $10 \mathrm{mg} / \mathrm{kg} P O$ & $\Delta$ & Second control & $\Delta$ & Control & $10 \mathrm{mg} / \mathrm{kg}$ PO & $\Delta$ & Second control & $\Delta$ \\
\hline $\mathrm{W}(\mathrm{sec})$ & $12600 \pm 501$ & $11591 \pm 525$ & -8 & $13730 \pm 812$ & +9 & $12982 \pm 559$ & $11679 \pm 219$ & -10 & $12459 \pm 646$ & -4 \\
\hline non-REM (sec) & $8491 \pm 444$ & $9766 \pm 504$ & $+15^{*}$ & $7450 \pm 689$ & $-12^{*}$ & $8162 \pm 521$ & $9450 \pm 186$ & $+16^{*}$ & $8619 \pm 695$ & +6 \\
\hline nSWD & $208 \pm 19$ & $126 \pm 20$ & $-39^{*}$ & $158 \pm 16$ & $-24^{*}$ & $186 \pm 23$ & $108 \pm$ & $-42^{*}$ & $256 \pm 50$ & +38 \\
\hline dSWD (sec.) & $1805 \pm 192$ & $1261 \pm 285$ & $-30^{*}$ & $1880 \pm 269$ & +4 & $1296 \pm 127$ & $881 \pm 92$ & -32 & $2162 \pm 20$ & $+67^{*}$ \\
\hline
\end{tabular}

$* p \leq 0.05$ Student's $t$-test for paired values. For legends, see Table 1 .

their administration. Zolpidem induced a decrease of nonREM sleep during waking (dark) period, which was not found for midazolam. Zolpidem does not appear to cause rebound insomnia or to have residual sedative effects in the morning in humans (19), although these phenomena are well known with benzodiazepines $(14,17,21)$.

The decrease in the number and duration of spike-wave discharges after midazolam was expected considering the wellknown antiepileptic action of benzodiazepines (22). However, the reduction in spike-wave discharges seen with zolpidem was as marked as that of midazolam. It is known that the anticonvulsant action of zolpidem in pentylenetetrazol-induced seizures or in electroshock convulsions is less than those of the benzodiazepines flunitrazepam and midazolam (10). Thus, zolpidem is 225 and 69 times less potent than flunitrazepam and midazolam, respectively, in pentylenetetrazol-induced convulsions, and 13 and 8 times less potent in electroshock convulsions. On the other hand, zolpidem is more active in convulsive models that involve impairment in GABAergic transmission, e.g., isoniazid-induced convulsions. It possesses the same or an even higher efficacy as compared to flunitrazepam and midazolam, in this model (30). The present data shows that midazolam and zolpidem are equally effective in suppressing spike-wave discharges, and these effects seem to be correlated with their hypnotic and antiisoniazid potency.

The decrease in the number of spike-wave discharges fol- lowing midazolam was followed by an increase in the number of spike-wave discharges. To our knowledge, rebound effects on spontaneous epileptic activity have not previously been reported. Only following abrupt cessation of chronic benzodiazepine administration was an increase in susceptibility for epileptic seizures reported (23). The rebound effects seen only on spike-wave discharges but not on sleep after midazolam could reflect a poorer quality of vigilance, with an increase of quiet wakefulness-drowsiness periods, because spike-wave discharges preferentially occur during periods with a low level of vigilance (12). In contrast, zolpidem maintains an adequate level of vigilance after its hypnotic effect during the waking (dark) period without rebound of spike-wave discharges.

In all, the present data show comparable hypnotic effects of zolpidem and midazolam in rats with a different genotype than commonly used. They further suggest an equal potency of these drugs to suppress spike-wave discharges in WAG/Rij rats. Finally, the data show a rebound effect on spike-wave activity for midazolam that could reflect a poorer quality of vigilance, but this warrants further investigation.

\section{ACKNOWLEDGEMENTS}

The authors gratefully acknowledge A. Clemente and C. Laufrais for their skilled experimental assistance and I. Chartouni for her secretarial help.

\section{REFERENCES}

1. Arbilla, S.; Depoortere, H.; George, P.; Langer, S. Z. Pharmacological profile of the imidazopyridine zolpidem at benzodiazepine receptors and electrocorticogram in rats. Naunyn Schmiedebergs Arch. Pharmacol. 330:248-251; 1985.

2. Coenen, A. M. L.; Van Hulzen, Z. J. M.; van Luijtelaar, E. L. J. M. Paradoxical sleep in the dark period of the rat: A dissociation between electrophysiological and behavioral characteristics. Behav. Neurol. Biol. 37:350-356; 1983.

3. Coenen, A. M. L.; van Luijtelaar, E. L. J. M. Effects of diazepam and two beta-carbolines on epileptic activity and on EEG behavior in rats with absence seizures. Pharmacol. Biochem. Behav. 31:1-9; 1989.

4. Coenen, A. M. L.; Drinkenburg, W. H. I, M.; Inoue, M.; van Luijtelaar, E. L. J. M. Genetic models of absence epilepsy, with emphasis on the WAG/Rij strain of rats. Epilepsy Res. 12:75-86; 1992.

5. Coenen, A. M. L.; Stephens, D. N.; van Luijtelaar, E. L. J. M. Effects of the beta-carboline abecarnil on epileptic activity, EEG, sleep and behavior in rats. Pharmacol. Biochem. Behav. 42:401$405 ; 1992$.

6. Dement, W. C.; Seidel, W.; Carskadon, M. A. Issues in the diagnosis and treatment of insomnia. Psychopharmacology (Berlin) $\mathrm{S} 1: 11-43 ; 1984$.

7. Depoortere, H. Some aspects of the polygraphic studies on sleepwakefulness cycle in the rat. Waking Sleeping 4:47-62; 1980.

8. Depoortere, H.; Granger, P. Differentiation of EEG sleep stages in the rat and the cat by automatic analysis. In: Kubicki, S.; Herrmann, W. M., eds. Methods of sleep research. Stuttgart: Gustav Fischer; 1985:37-45.

9. Depoortere, H.; Decobert, M.; Granger, P.; Riou-Merle, F. Hypnotics: Clinical value of pharmaco-EEG methods. Neuropsychobiology 16:157-162; 1986 .

10. Depoortere, H.; Zivkovic, B.; Lloyd, K. G.; Sanger, D. J.; Perrault, G.; Langer, S. Z.; Bartholini, G. Zolpidem, a novel nonbenzodiazepine hypnotic. I. Neuropharmacological and behavioral effects. J. Pharmacol. Exp. Ther. 237:649-658, 1986.

11. Depoortere, H.; Decobert, M.; Riou-Merle, F.; Granger, P. Pharmaco-EEG profile of zolpidem: An imidazopyridine hypnotic agent. In: Sauvanet, J. P.; Langer, S. Z.; Morselli, P. L., eds. Imidazopyridines in sleep disorders. New York: Raven Press; 1988:81-96.

12. Drinkenburg, W. H. I. M.; Coenen, A. M. L.; Vossen, J. H. M.; 
van Luijtelaar, E. L. J. M. Spike-wave discharges and sleep-wake states in rats with absence epilepsy. Epilepsy Res. 9:218-224; 1991.

13. Gandolfo, G.; Romettino, S.; Gottesmann, C.; van Luijtelaar, G.; Coenen, A. Genetically epileptic rats show a pronounced intermediate stage of sleep. Physiol. Behav. 47:213-215; 1990.

14. Gillin, J. C.; Spinweber, C. L.; Johnson, L. C. Rebound insomnia: A critical review. J. Clin. Psychopharmacol. 9:161-172; 1989.

15. Granger, P.; Riou-Merle, F.; Heuvingh, R.; Lucas, A.; Decobert, M.; Leonardon, J.; Rousseau, A.; Clemente, A.; Depoortere, H. Qualitative and quantitative analysis of the sleep-wakefulness cycle in animals using normalized slope descriptors (NSD). In: Court, L.; Trocherie, S., Doucet, J., eds. Le traitement du signal en électrophysiologie expérimentale et clinique du système nerveux central. Tome II. Edition du Commissariat à l'Energie Atomique; 1986:493-508.

16. O'Hanlon, J. F.; Haak, T. W.; Blaauw, G. J.; Riemersma, J. B. J. Diazepam impairs lateral position control in highway driving. Science 217:79-81; 1987.

17. Kales, A.; Soldatos, C. R.; Bixler, E. O.; Kales, J. D. Rebound insomnia and rebound anxiety: A review. Pharmacology 26:121$137 ; 1983$.

18. Kiyono, S.; Seo, M. L.; Shibagaki, M. Effects of rearing environments upon sleep-waking parameters in rats. Physiol. Behav. 26(3):391-394; 1981 .

19. Langtry, H. D.; Benfield, B. Zolpidem, a review of its pharmacodynamic and pharmacokinetic properties and therapeutic potential. Drugs 40:291-333; 1990.

20. Lister, G. J. The amnestic action of benzodiazepines in man. Neurosci. Behav. Rev. 9:87-94; 1985.

21. Oswald, I.; Adam, K.; Borrow, S.; Idzikowski, C. The effects of two hypnotics in sleep, subjective feeling and skilled performance. In: Passouant, P.; Oswald, I., eds. Pharmacology of the states of alertness. Oxford: Pergamon Press; 1979:51-63.
22. Peeters, B. W. M. M.; Spooren, W. P. J. M.; van Luijtelaar, E. L. J. M.; Coenen, A. M. L.The WAG/Rij model for absence epilepsy: Anticonvulsivant drug evaluation. Neurosci. Res. Commun. 2:93-97; 1988.

23. Schöpf, J. Withdrawal phenomena after long-term administration of benzodiazepines. A review of recent investigations. Pharmacopsychiatria 16:1-8; 1983.

24. Stephens, D. N.; Schneider, H. H.; Kehr, W.; Andrews, J. S.; Rettig, K. J.; Turski, L.; Schiechen, R.; Turner, J. D.; Jensen, L. H.; Petersen, E. N.; Honore, T.; Bondo Hansen, J. Abecarnil, a metabolically stable anxioselective beta-carboline acting at benzodiazepine receptors. J. Pharmacol. Exp. Ther. 253:334-343;1990.

25. Unrug-Neervoort, A.; van Luijtelaar, G.; Coenen, A. Cognition and vigilance: Differential effects of diazepam and buspirone on memory and psychomotor performance. Neuropsychobiology 26 : 146-150; 1992.

26. Van Gool, W. A.; Mirmiran, M. Effects of aging and housing in an enriched environment on sleep-wake patterns in rats. Sleep 9: 335-347; 1986.

27. van Luijtelaar, E. L. J. M.; Coenen, A. M. L. Two types of electrocortical paroxyms in an inbred strain of rats. Neurosci. Lett. 70:393-397; 1986.

28. van Luijtelaar, E. L. J. M.; Coenen, A. M. L. Circadian rhythmicity in absence epilepsy in rats. Epilespy Res. 2:331-336; 1988.

29. van Luijtelaar, E. L. J. M.; Coenen, A. M. L. The behavorial pharmacology of sleep. In: Van Haaren, F., ed. Methods in behavioral pharmacology. Amsterdam: Elsevier Science Publishers; 1993:575-602.

30. Zivkovic, B.; Perrault, G.; Morel, E.; Sanger, D. J. Comparative pharmacology of zolpidem and other hypnotics and sleep inducers. In: Sauvanet, J. P.; Langer, S. Z.; Morselli, P. L., eds. Imidazopyridines in sleep disorders. New York: Raven Press; 1988:97-109. 